\title{
Hydrochloric Acid Leaching Study of Rare Earth Elements from Moroccan Phosphate
}

\author{
Marouane Amine (iD, Fatima Asafar, Latifa Bilali, and Mehdi Nadifiyine \\ Laboratoire de Réactivité des Matériaux et Optimisation des Procédés «REMATOP», Department of Chemistry, \\ Faculty of Science Semlalia, Cadi Ayyad University, B.P. 2390, Marrakech 40000, Morocco
}

Correspondence should be addressed to Marouane Amine; marouane.amin@gmail.com

Received 25 February 2019; Revised 1 June 2019; Accepted 8 July 2019; Published 7 August 2019

Academic Editor: Alberto Figoli

Copyright (c) 2019 Marouane Amine et al. This is an open access article distributed under the Creative Commons Attribution License, which permits unrestricted use, distribution, and reproduction in any medium, provided the original work is properly cited.

\begin{abstract}
As part of the valorization of the Moroccan phosphate rock by extraction of rare earths, different experiments on natural Moroccan phosphate from the Gantour Basin (basin of phosphate in the Youssoufia area) were done in the REMATOP laboratory. The response surface methodology was used to study the effects of the influence of different parameters (acid concentration, solid/ liquid ratio, duration of the reaction, stirring speed, and temperature) on the progress of the phosphate rock's dissolution process to determine the optimal parameters for the extraction of rare earths. The analyses were made at the same time on the mineral matrix and the solutions resulting from the attack of this matrix by different concentrations of hydrochloric acid. The rare earth analyses done by the ICP-MS technique have shown an overall amount of rare earths ( $\Sigma$ REs) of 228.408 ppm with the existence of yttrium as the major element.
\end{abstract}

\section{Introduction}

Rare earth elements (REEs) include the 15 elements of lanthanide group from lanthanum to lutetium, coupled with chemically similar yttrium and infrequently scandium [1]. There are three main existing forms of rare earths in nature: independent rare earth minerals, weathered crust elutiondeposited REEs, and isomorphism substitution REEs [2]. Recently, many research studies have focused on the recovery of REEs from second resources such as phosphate rock that is associated with a trace amount of REEs [3].

At present, Morocco has the largest phosphate reserve in the world. This wealth is estimated at more than 90 billion $\mathrm{m}^{3}$ [4]. The deposits exist in a number of basins located in different geographical domains: Gantour (Youssoufia and Benguerir), Messkala (Chichaoua), Oued Eddahab (Boucraâ), and Ouled Abdoun (Khouribga) [5]. As a result, Moroccan phosphate is one of the most important national wealth and its exploitation could be the subject of various innovations. In addition to the traditionally known forms of exploitation (sale of raw phosphate, manufacture of phosphoric acid, and fertilizers of food supplements, etc.), other potential exploitations are currently of major interest in the research and development strategy such as the recovery of rare metals. To this effect, our REMATOP laboratory has been interested in this valorization of Moroccan phosphate rock; the main objective of this study is to determine the rare earth content in the Moroccan phosphate as well as the optimal leaching conditions for their extraction.

Various acids are used as leaching agents in recovery studies of rare earths from phosphate rock by hydrometallurgical processes such as $\mathrm{H}_{2} \mathrm{SO}_{4}, \mathrm{HNO}_{3}, \mathrm{H}_{3} \mathrm{PO}_{4}$, and $\mathrm{HCL}$ [6]. Because of the impossibility of recovering REEs from phosphate by sulfuric acid (the most economical acid and already adopted by the traditional way of decomposition of phosphate rock) [7], we worked with $\mathrm{HCl}$ as a more economical leaching agent compared to $\mathrm{HNO}_{3}$ and $\mathrm{H}_{3} \mathrm{PO}_{4}$. The present work is one of the first steps towards valorization and production of other substances from phosphate besides phosphoric acid (the traditional product). The potential increase in the cost of fertilizers, linked to the prices of hydrochloric acid, can be offset by the additional production of byproducts of high commercial value such as rare earths. 


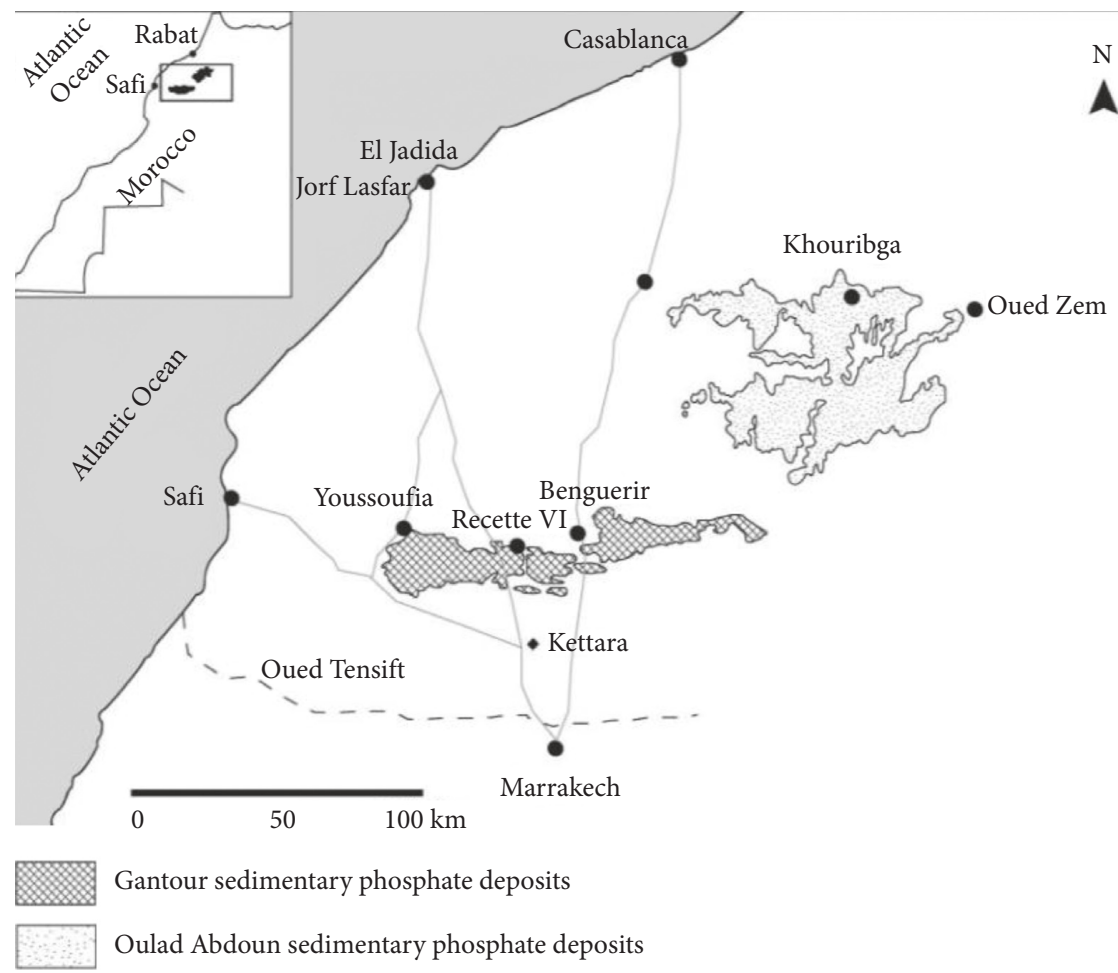

Figure 1: Local situation of Gantour and Oulad Abdoun sedimentary phosphate deposits [9].

In addition to the nature of the acid "leaching agent", the leaching of rare earth elements from phosphate rock is influenced by many factors. For this reason, experimental design has been used to control the different factors that influence in the leaching process in order to optimize experimental conditions. The influential factors are optimized using response surface methodology and multicriteria optimization with a Doehlert design and desirability function [6-8].

\section{Experimental}

2.1. Materials. The experimental study is based on samples of the natural phosphate. The samples were provided by OCP group. The natural black phosphate samples chosen for this study originated from the fields of Youssoufia (Morocco). This phosphate is apatitic. The general properties of the Youssoufia phosphate and the structure of the fluorapatite, which is the most stable component in the natural state with a formula $\mathrm{Ca}_{10}\left(\mathrm{PO}_{4}\right)_{6} \mathrm{~F}_{2}$, have been described in previous works [4].

Figure 1 deposits the local of Gantour and Oulad Abdoun sedimentary phosphate. Our study used samples from the Youssoufia deposit (Gantour Basin).

2.2. Characterization of Youssoufia Rock Phosphate: XRD, ICP/MS, FTIR, and SEM. The sum of the analytical techniques used is subdivided into two main types:

(i) Techniques illustrating the chemical and mineralogical characteristics of our sample (the phosphate rock of Youssoufia): X-Ray diffraction (XRD),
TABLE 1: Mineralogical composition of the phosphate.

\begin{tabular}{lc}
\hline Mineralogical characteristics & Percentages (\%wt) \\
\hline Apatite, $\mathrm{Ca}_{10}\left(\mathrm{PO}_{4}\right)_{6} \mathrm{~F}_{2}$ & 90 \\
Calcite, $\mathrm{CaCO}_{3}$ & 2.7 \\
Dolomite, $\mathrm{CaMgCO}_{3}$ & 1.7 \\
Quartz, $\mathrm{SiO}_{2}$ & 1.4 \\
Organic matter & 2.8 \\
Amorphous silica & 0.2 \\
Pyrite & 0.3 \\
\hline
\end{tabular}

scanning electron microscopy (SEM), and Fouriertransform infrared spectroscopy (FTIR)

(ii) Analysis of phosphate and the resulting solution of hydrochloric leaching by ICP/MS to determine its rare earth content

2.2.1. X-Ray Diffraction (XRD) Characterization. The general characteristics of phosphate were determined using XRD mineralogical quantification. Table 1 lists the mineralogical composition of the phosphate. The main constituents of the phosphate are apatite, calcite, and organic matter (Table 1).

Figure 2 presents the diffraction pattern performed on powdered samples, obtained by grinding the raw phosphate samples at $25^{\circ} \mathrm{C}$. The diffraction pattern of the raw phosphate samples (Figure 2) shows various lines. Some can be attributed to the carbonate fluorapatite contained in the ore, and others correspond to the carbonate $\mathrm{CaCO}_{3}$ phase and quartz.

2.2.2. Inductively Coupled Plasma Mass Spectrometry (ICP$M S)$. The chemical composition of phosphate found by 


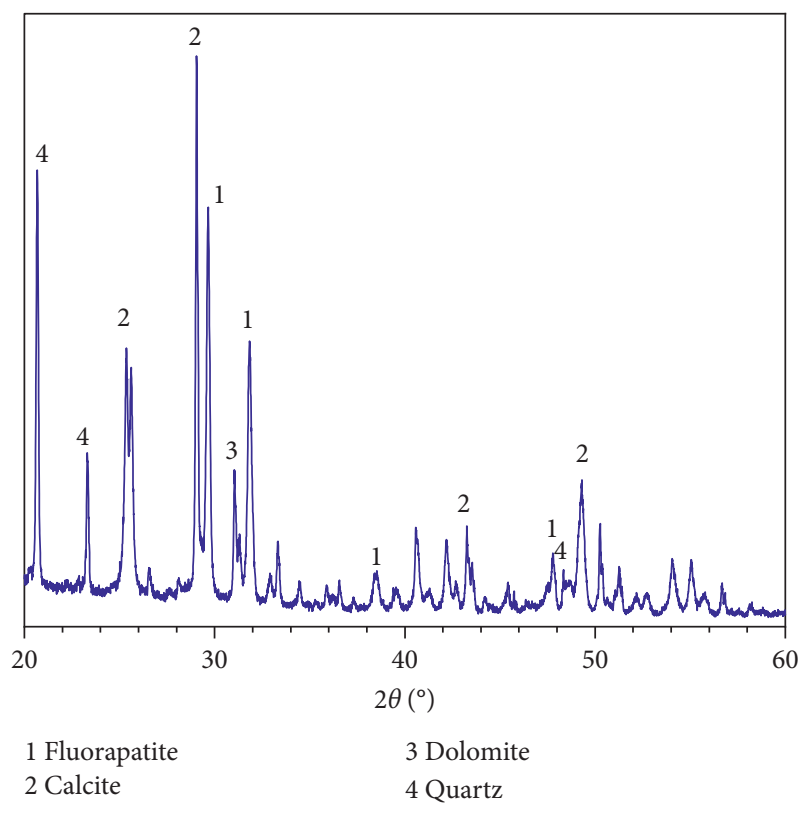

FIgURE 2: X-Ray diffraction pattern of the raw phosphate.

using ICP/MS is given in Table 2 and Table 3 . We note that $\mathrm{CaO}$ and $\mathrm{P}_{2} \mathrm{O}_{5}$ are the most abundant compounds. The majority of the different REEs are yttrium (143 ppm), lanthanum (24.06 ppm), and neodymium (17.52 ppm). The sum of the minor elements ( $(\mathrm{MEs})$ such as $\mathrm{Ge}, \mathrm{Se}$, and $\mathrm{Sn}$ is $3538.1 \mathrm{ppm}$.

2.2.3. Infrared Spectroscopy. The presence of apatite phases and carbonate in bright phosphate is confirmed by infrared spectroscopy techniques.

(i) The large band between 3750 and $3000 \mathrm{~cm}^{-1}$ corresponds to the stretching mode of the absorbed water at $3515 \mathrm{~cm}^{-1}$ and the bending mode at 3450 . It is a combination of the antisymmetric stretching mode, the symmetric stretching mode, and an overtone of the bending mode [10].

(ii) The $2361 \mathrm{~cm}^{-1}$ peak corresponds to the atmospheric $\mathrm{CO}_{2}[11]$.

(iii) The $1645 \mathrm{~cm}^{-1}$ peak corresponds to the third vibration mode of the adsorbed water molecule known as angular deformity [11].

(iv) The $1456 \mathrm{~cm}^{-1}$ double peak is assigned to carbonate $\mathrm{v}_{3}[12]$.

(v) The peaks observed at $1040 \mathrm{~cm}^{-1}$ and $963 \mathrm{~cm}^{-1}$ are related to the stretching mode $\mathrm{v}_{3}$ and to the stretching mode $\mathrm{v}_{1}$ of $\mathrm{PO}_{4}{ }^{3-}$, respectively [13].

(vi) The $885 \mathrm{~cm}^{-1}$ double peak is assigned to carbonate $\mathrm{v}_{2}[12]$.

(vii) The peaks around $604 \mathrm{~cm}^{-1}$ are related to the vibration mode $\mathrm{v}_{4}$ of $\mathrm{PO}_{4}{ }^{3-}$ [13].

The group of $\mathrm{PO}_{4}{ }^{3-}$ peaks detected in Figure 3 by FTIR of natural phosphate proves the presence of fluorapatite in our
TABLE 2: Chemical composition of the phosphate.

\begin{tabular}{lc}
\hline Chemical characteristics & Percentages (\%wt) \\
\hline $\mathrm{P}_{2} \mathrm{O}_{5}$ & 28 \\
$\mathrm{SiO}_{2}$ & 3.25 \\
$\mathrm{Al}_{2} \mathrm{O}_{3}$ & 1.47 \\
$\mathrm{Fe}_{2} \mathrm{O}_{3}$ & 0.34 \\
$\mathrm{CaO}$ & 45.05 \\
$\mathrm{MgO}$ & 1.20 \\
$\mathrm{KO}_{2}$ & 0.52 \\
$\mathrm{MnO}$ & $<0.01$ \\
$\mathrm{TiO}_{2}$ & 0.03 \\
$\mathrm{BPL}$ & 61.18
\end{tabular}

BPL (bone phosphate of lime) $=2.185 \mathrm{P}_{2} \mathrm{O}_{5}$.

TABLe 3: Descriptive statistics of REEs (ppm) and minor elements $(\mathrm{ppm})$ in natural phosphate rock of Youssoufia.

\begin{tabular}{lc}
\hline Element & ppm \\
\hline $\mathrm{Y}$ & 143 \\
$\mathrm{La}$ & 24.06 \\
$\mathrm{Ce}$ & 13 \\
$\mathrm{Pr}$ & 3.626 \\
$\mathrm{Nd}$ & 17.52 \\
$\mathrm{Sm}$ & 3.681 \\
$\mathrm{Eu}$ & 1.008 \\
$\mathrm{Gd}$ & 5.143 \\
$\mathrm{~Tb}$ & 0.8387 \\
$\mathrm{Dy}$ & 5.672 \\
$\mathrm{Ho}$ & 1.303 \\
$\mathrm{Er}$ & 4.315 \\
$\mathrm{Tm}$ & 0.6205 \\
$\mathrm{Yb}$ & 4.2 \\
$\mathrm{Lu}$ & 0.7843 \\
$\mathrm{NREEs}$ & 228.408 \\
$\sum \mathrm{MEs}$ & 3538.1 \\
\hline
\end{tabular}

phosphate sample which has already been proved by the use of XRD (Figure 2), while the group of $\mathrm{CO}_{3}{ }^{2-}$ peaks proves the presence of calcite and dolomite [14].

2.2.4. Scanning Electron Microscopy (SEM). The observation by a scanning electron microscope (SEM) shows that Youssoufia phosphate rock before attack with hydrochloric acid consists essentially of irregularly shaped phosphate particles and sometimes rounded (Figures 4 and 5). This variety of particles along with apatite is explained by the presence of bone debris and organic debris as well as quartz grains. These observations confirm the structure previously identified by X-ray diffraction (Figure 5).

\subsection{Methods}

2.3.1. Sample Preparation. The homogeneity of the material and its particle size is an important parameter that should be well controlled. For this, we worked with a particle size $<80 \mu \mathrm{m}$. In the study of hydrochloric leaching, we have used homogeneous samples provided from the Youssoufia region. The objective of the leaching manipulations is to study the influence of certain parameters (acid concentration, solid/ 


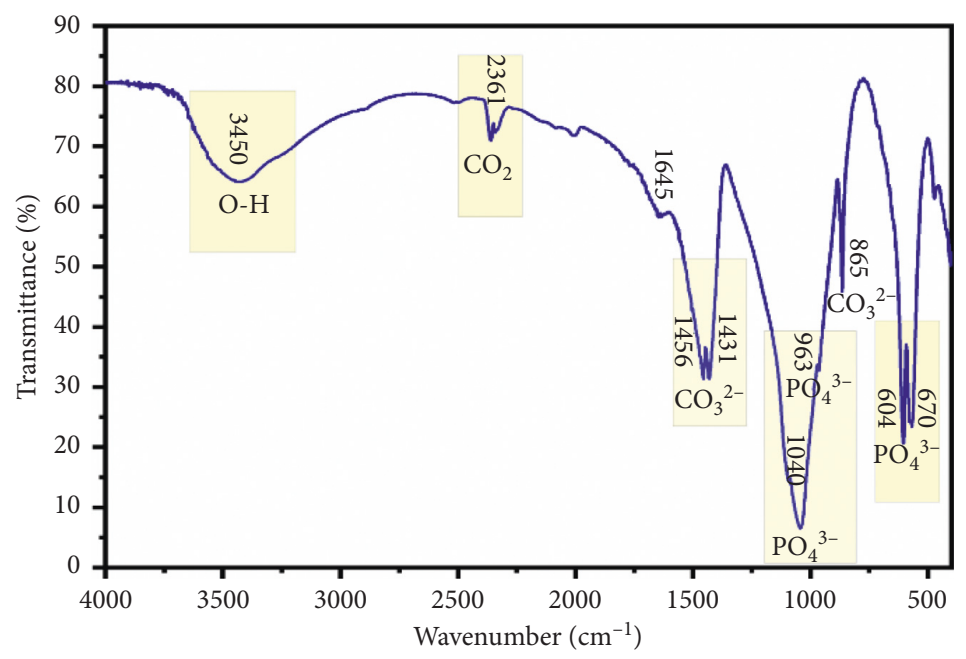

FIGURE 3: Infrared spectrum of natural phosphate.

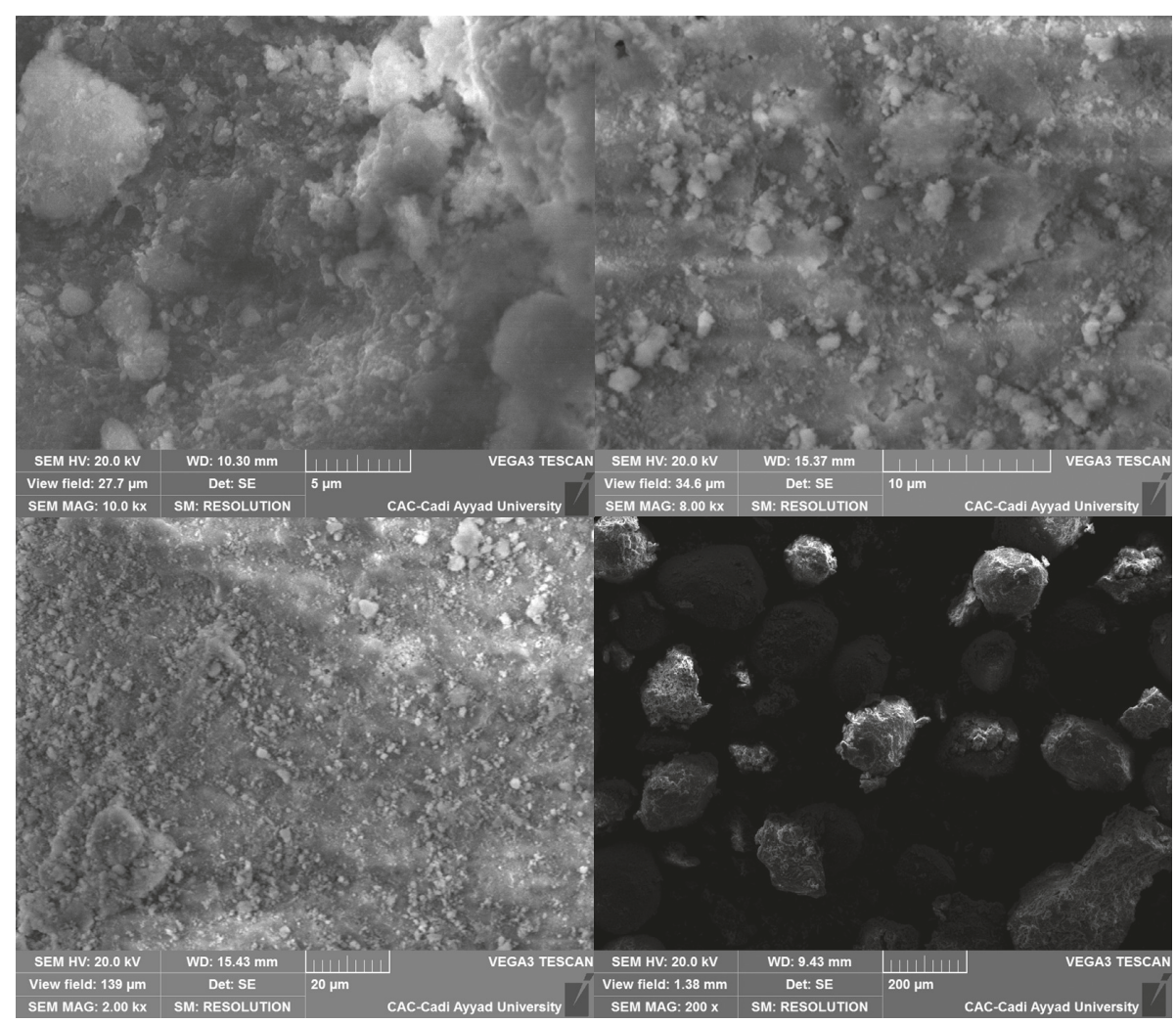

FIGURE 4: Morphological observation of the surface of natural phosphate before treatment.

liquid ratio, reaction time, stirring speed, and temperature) on the progress of the dissolution process of the phosphate rock in order to define the optimal parameters allowing the maximum dissolution of the rare earths.

A defined volume of hydrochloric acid $(\mathrm{HCl}, d=1.19)$ was added to a preweighed amount of phosphate. The tests were made with hydrochloric acid at various concentrations varying between $13 \%$ and $23 \%$ with stirring of $100 \mathrm{rpm}$ to $300 \mathrm{rpm}$, and the series of tests were conducted with a solid/ liquid ratio of $20 \%$ to $50 \%$. The reaction temperature is $25^{\circ} \mathrm{C}$ to $65^{\circ} \mathrm{C}$, and the duration of the reaction is 30 to $60 \mathrm{~min}$
(Table 4). At the end of the reaction, the mixture obtained was subjected to $30 \mathrm{~min}$ of centrifugation. Then, an analysis of ICP/MS was applied on the resulting liquid factors and field of study.

Table 4 presents the list of all the factors adopted by our study to influence hydrochloric leaching. To carry out the sample analyses by the ICP-MS technique, we worked with a factor dilution of twenty (Table 5).

Note that during the attack of the crude phosphate with hydrochloric acid for experiments 10, 14, and 16 (Table 5), there is a formation of foam which is the 


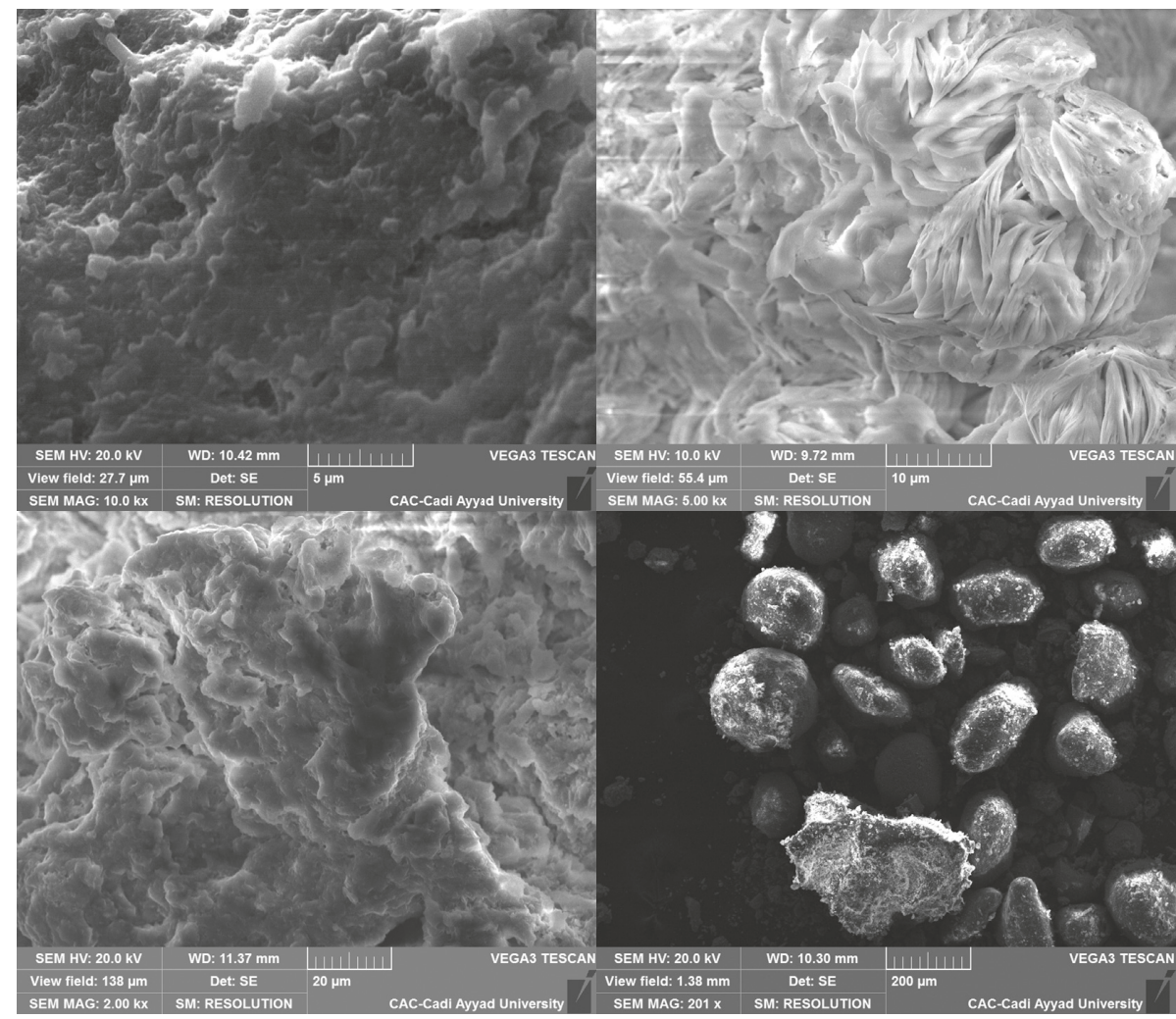

FIgURE 5: Morphological observation of the surface of natural phosphate after treatment.

Table 4: Experimental domain for the Doehlert experimental design.

\begin{tabular}{lcccccc}
\hline & Factor $(\mathrm{XI})$ & $\mathrm{HCl}(\%)$ & Temperature $\left({ }^{\circ} \mathrm{C}\right)$ & Stirring $(\mathrm{rpm})$ & S/L ratio $(\%)$ & Time $(\mathrm{min})$ \\
\hline Level 1 & -1 & 13 & 25 & 100 & 20 & 30 \\
Level 2 & 0 & 18 & 45 & 200 & 35 & 45 \\
Level 3 & +1 & 23 & 65 & 300 & 50 & 60 \\
\hline
\end{tabular}

organic matter. In order to avoid this problem, hydrochloric acid is gradually added $(2 \mathrm{~mL} / \mathrm{min})$. The phosphoric acid is produced according to the following reactions [4]:

$$
\begin{aligned}
& \mathrm{Ca}_{10}\left(\mathrm{PO}_{4}\right) 6_{\mathrm{F} 2}+14 \mathrm{HCl} \longrightarrow 3 \mathrm{Ca}\left(\mathrm{H}_{2} \mathrm{PO}_{4}\right)_{2}+7 \mathrm{CaCl}_{2}+2 \mathrm{HF} \\
& \mathrm{Ca}_{10}\left(\mathrm{PO}_{4}\right) 6_{\mathrm{F} 2}+20 \mathrm{HCl} \longrightarrow 6_{\mathrm{H} 3} \mathrm{PO}_{4}+7 \mathrm{CaCl}_{2}+2 \mathrm{HF}
\end{aligned}
$$

2.3.2. Design of Experiments. The response surface methodology (RSM) was used to optimize operating conditions allowing the maximum dissolution of the rare earths. This method allows one to seek optimum levels of various factors to achieve a desired response level. The five factors influencing phosphate rock dissolution (the concentration of $\mathrm{HCl}$, temperature, stirring, solid/liquid ratio, and time) were coded respectively $\left(X_{1}, X_{2}, X_{3}, X_{4}\right.$, and $\left.X_{5}\right)$, and the responses studied gave the concentration of rare earths in ppm ( $Y$, REEs). We worked with five factors that correspond to 21 tests performed including five to calculate both the error variance and the reproducibility of the test data. A polynomial model of the first degree was used, and the model can be written as

$$
Y=b_{0}+b_{1} X_{1}+b_{2} X_{2}+b_{3} X_{3}+b_{4} X_{4}+b_{5} X_{5} .
$$

$Y$ : studied answer; $X_{i}$ : investigated factor ( $i$ varies from 1 to 5 ); $b_{0}$ : a constant; $b_{i}$ : main effect of factor $i$. The experimental design was developed using NEMROD software [15].

2.3.3. Methodology for Research Using Optimal Design. This design permits to represent the responses studied in all experimental domains of these two factors. The experimental design and responses are given in Table 5.

\section{Results and Discussion}

3.1. Analysis of $Y$ Response. Analysis of $Y$ (the concentration of rare earths/20) From the results listed in (Table 5), we see that the soil concentration varies between $13.970 \mathrm{ppm}$ and $2.020 \mathrm{ppm}$, the maximum concentration was around $13.970 \mathrm{ppm}$ (test 4 ), and the minimum concentration was $2.020 \mathrm{ppm}$ (test 13). The estimation coefficients of the postulated model (equation (2)) were determined by the leastsquares method using NEMROD software. The interpretation of the coefficients and main effects of the factors $\left(b_{i}\right)$ was performed from statistical tests on the coefficients. The 
TABLe 5: Experimental design and result.

\begin{tabular}{|c|c|c|c|c|c|c|}
\hline No. of experiments & $X_{1}: \mathrm{HCl}(\%)$ & $X_{2}:$ temperature $\left({ }^{\circ} \mathrm{C}\right)$ & $X_{3}$ : stirring $(\mathrm{rpm})$ & $X_{4}:$ S/L ratio $(\%)$ & $X_{5}:$ time $(\mathrm{min})$ & $Y:$ response $(\mathrm{ppm})$ \\
\hline 1 & 13 & 25 & 100 & 20 & 60 & 3.870 \\
\hline 2 & 23 & 25 & 100 & 20 & 30 & 8.932 \\
\hline 3 & 12 & 65 & 100 & 20 & 30 & 4.801 \\
\hline 4 & 23 & 65 & 100 & 20 & 60 & 13.970 \\
\hline 5 & 13 & 25 & 300 & 20 & 30 & 3.104 \\
\hline 6 & 23 & 25 & 300 & 20 & 60 & 11.452 \\
\hline 7 & 13 & 65 & 300 & 20 & 60 & 7.523 \\
\hline 8 & 23 & 65 & 300 & 20 & 30 & 10.134 \\
\hline 9 & 13 & 25 & 100 & 50 & 30 & 2.055 \\
\hline 10 & 23 & 25 & 100 & 50 & 60 & 4.833 \\
\hline 11 & 13 & 65 & 100 & 50 & 60 & 2.144 \\
\hline 12 & 23 & 65 & 100 & 50 & 30 & 4.343 \\
\hline 13 & 13 & 25 & 300 & 50 & 60 & 2.020 \\
\hline 14 & 23 & 25 & 300 & 50 & 30 & 5.343 \\
\hline 15 & 13 & 65 & 300 & 50 & 30 & 2.430 \\
\hline 16 & 23 & 65 & 300 & 50 & 60 & 6.343 \\
\hline 17 & 18 & 45 & 200 & 35 & 45 & 2.903 \\
\hline 18 & 18 & 45 & 200 & 35 & 45 & 3.010 \\
\hline 19 & 18 & 45 & 200 & 35 & 45 & 3.001 \\
\hline 20 & 18 & 45 & 200 & 35 & 45 & 3.020 \\
\hline 21 & 18 & 45 & 200 & 35 & 45 & 3.890 \\
\hline
\end{tabular}

mathematical models were validated by verifying the correlation coefficient $\left(R^{2}\right)$ [15], where $R^{2}$ values are close to 1 . The difference between the experimental values and the predicted values was explained by these models [16]. To calculate the proportion of the total observed variability, an adjusted determination coefficient $\left(R_{\text {Adj }}^{2}\right)$ is used. After validation, for the graphical illustration of the response surfaces, different models are used.

\subsubsection{Study of the Estimates and Statistics of the Coefficients.} From Table 2, one can see that all of the factors are involved in different interactions with $\left(b_{0}=3.1648\right),\left(b_{1}=2.7398\right)$, $\left(b_{2}=0.8526\right),\left(b_{3}=-0.3290\right),\left(b_{4}=-5.2174\right)$, and $\left(b_{5}=1.5116\right)$. Therefore, the REE recovery can be described by equation (4)

$$
\begin{aligned}
Y= & b_{0}+b_{1} X_{1}+b_{2} X_{2}+b_{3} X_{3}+b_{4} X_{4}+b_{5} X_{5}, \\
Y= & 3.1648+2.7398 X_{1}+0.8526 X_{2}-0.3290 X_{3} \\
& -5.2174 X_{4}+1.5116 X_{5} .
\end{aligned}
$$

The model presents a high determination coefficient $R^{2}=0.99$, explaining $99 \%$ of the variability in the response. The adjusted determination coefficient is Adj. $R_{\mathrm{A}}^{2}=0.99$.

3.1.2. Three-Dimensional (3D) Response Surface and Isoresponse Curves for REE Recovery $(Y)$. 3D response surface plots were used to visualize the relationship between the response $(Y)$ and the experimental levels of each variable and the type of interactions between variables and to deduce the operating conditions leading to the optimal response [17]. Table 5 shows that the highest response $(13.970 \mathrm{ppm})$ was achieved with the greatest levels of $\mathrm{HCl}\left(X_{1}\right)$ and temperature $\left(X_{2}\right)$.

The Doehlert experimental design and experimental results are given in Table 5. In order to interpret the results,
TABle 6: Estimated values of coefficients for response $Y$.

\begin{tabular}{lccccc}
\hline Coefficient & Value & $\begin{array}{c}\text { F. } \\
\text { inflation }\end{array}$ & Ecart-Type & t. exp. & $\begin{array}{c}\text { Significance } \\
\%\end{array}$ \\
\hline$b_{0}$ & 3.1648 & & 0.1745858 & 18.13 & $<0.01^{* * *}$ \\
$b_{1}$ & 2.7398 & 1.41 & 0.19519286 & 14.04 & $<0.01^{* * *}$ \\
$b_{2}$ & 0.8526 & 1.13 & 0.16904198 & 5.04 & $0.395^{* *}$ \\
$b_{3}$ & -0.3290 & 1.41 & 0.19519286 & -1.69 & 15.3 \\
$b_{4}$ & -5.2174 & 1.23 & 0.2618787 & -19.92 & $<0.01^{* * *}$ \\
$b_{5}$ & 1.5116 & 1.13 & 0.16904198 & 8.94 & $0.0291^{* * *}$ \\
\hline
\end{tabular}

t. exp indicates the experimental value of the student rapport calculated as follows: t. $\exp =$ value/Ecart-Type. Value ${ }^{* * *}$ Statistically significant at the level $<99.99 \%$. ${ }^{* *}$ Statistically significant at the level $99 \%$.

the response surfaces were represented in the domains of interest of acid concentration, solid/liquid ratio, duration of the reaction, stirring speed, and temperature using NEMROD software (isoresponse curves). The estimated values of coefficients for responses yield $(Y)$ are given in Table 6.

In addition to temperature, acid concentration, and time, our study also tested the influence of stirring and S/L ratio that were neglected in other leaching optimization work of rare earths from phosphate as the case of the study conducted by Kim et al. [18].

Except for the time of leaching, the other reaction parameters have not been studied over continuous intervals (in general, fixing three arbitrary values to be tested for each parameter), which is one of the major gaps that we have avoided by the adoption of RSM $[19,20]$.

Figure 6 of the 3D response surface curves shows that the main parameters having a significant influence on the rare earth leaching process adopted are the following: acid percentage, temperature, and S/L ratio. Parameters act positively on the response (at high temperature and percentage of acid, the $Y$ response becomes more important), while the S/L ratio acts in the opposite direction (the increase of the ratio causes the decrease of $Y$ response). 


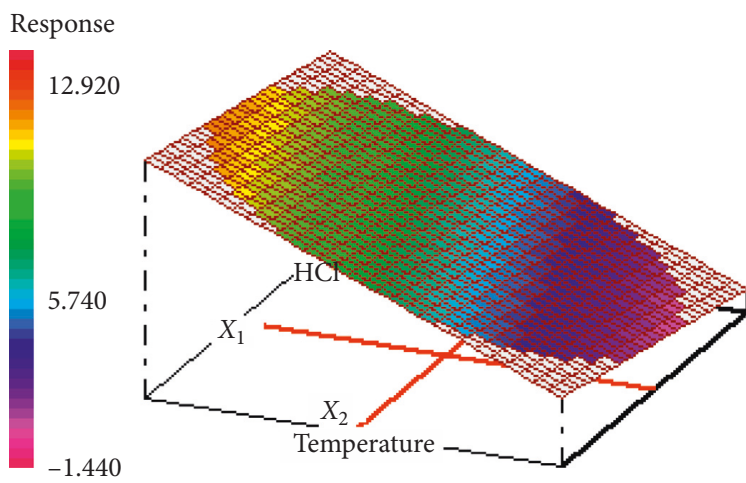

(a)

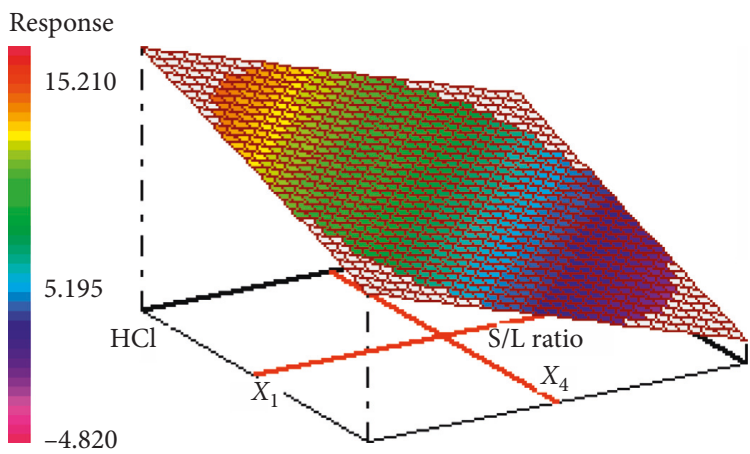

(c)

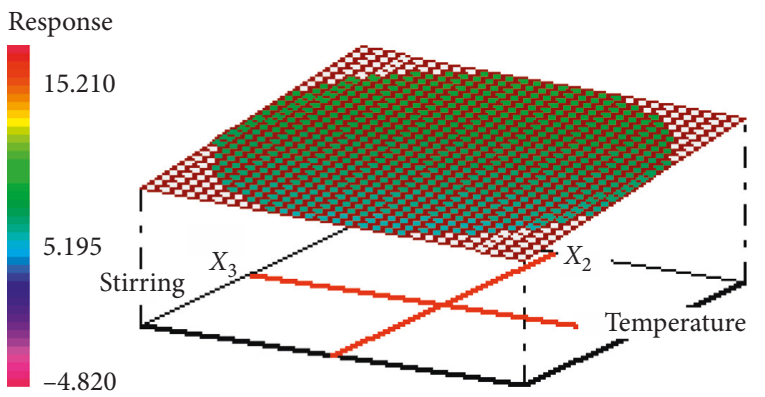

(e)

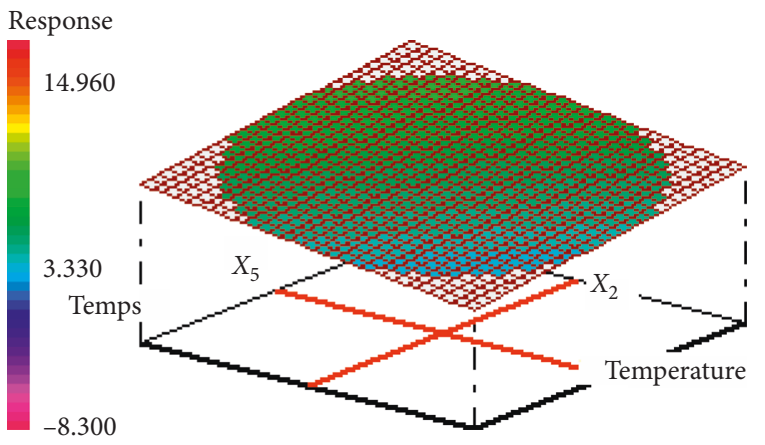

(g)

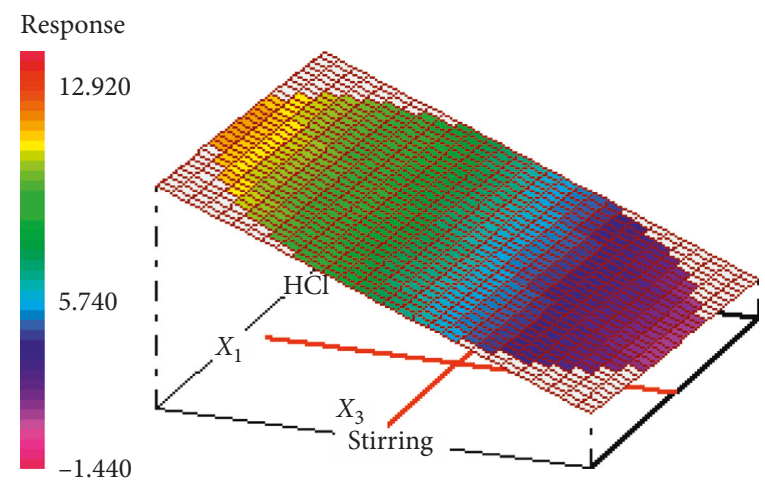

(b)

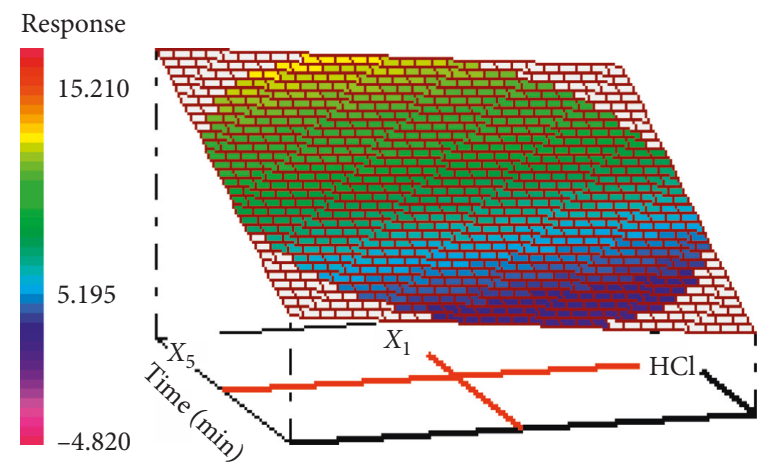

(d)

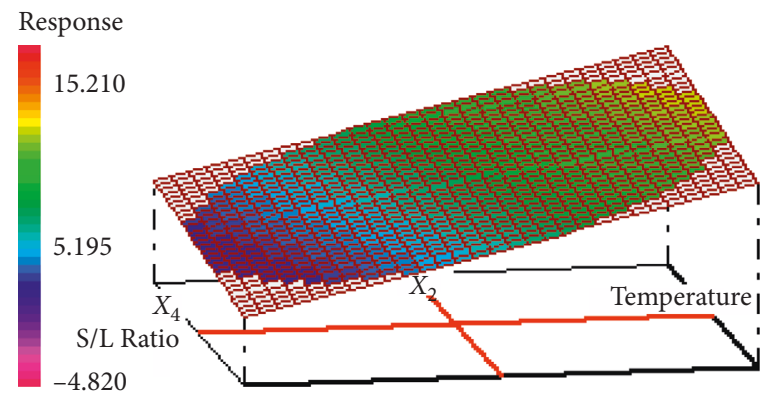

(f)

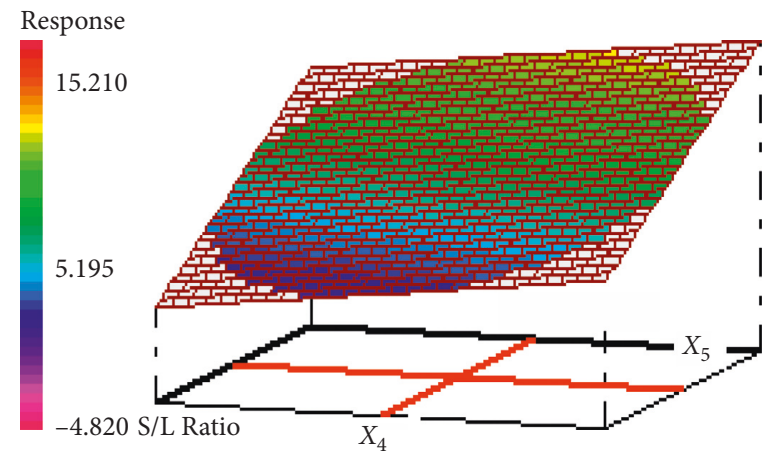

(h)

Figure 6: Continued. 


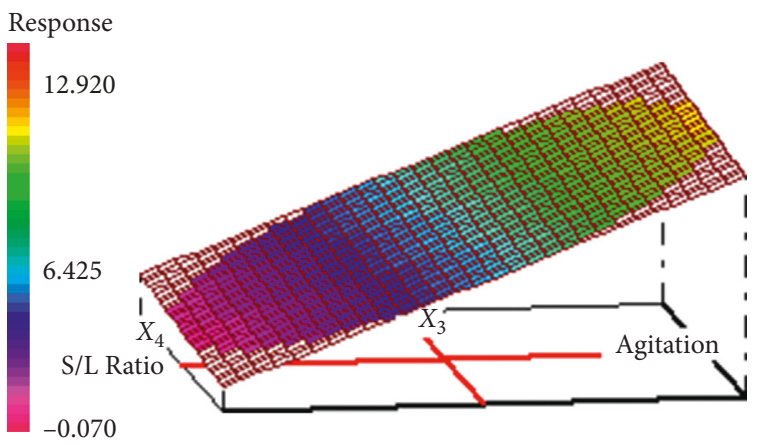

(i)

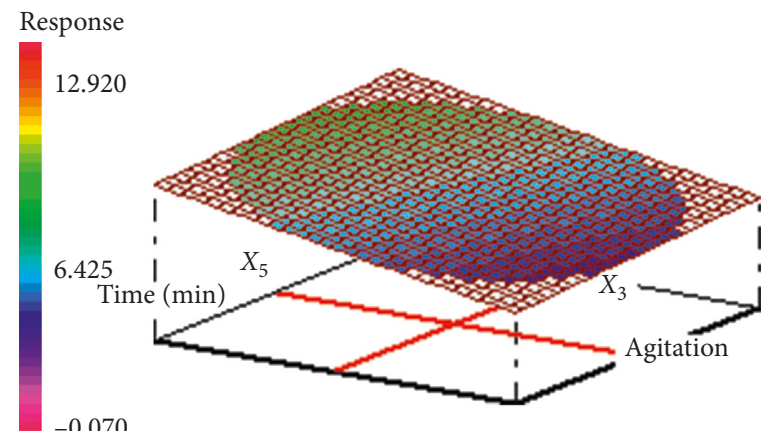

(j)

FIGURE 6: Response surface three-dimensional plots of the interaction of every two variables: (a) percentage of $\mathrm{HCl}\left(X_{1}\right)$ and temperature $\left(X_{2}\right)$; (b) percentage of $\mathrm{HCl}\left(X_{1}\right)$ and stirring speed $\left(X_{3}\right)$; (c) percentage of $\mathrm{HCl}\left(X_{1}\right)$ and S/L ratio $\left(X_{4}\right)$; (d) percentage of $\mathrm{HCl}\left(X_{1}\right)$ and time $\left(X_{5}\right)$; (e) temperature $\left(X_{2}\right)$ and stirring speed $\left(X_{3}\right)$; (f) temperature $\left(X_{2}\right)$ and $\mathrm{S} / \mathrm{L}$ ratio $\left(X_{4}\right)$; $(\mathrm{g})$ temperature $\left(X_{2}\right)$ and time $\left(X_{5}\right)$; $(\mathrm{h})$ stirring speed $\left(X_{3}\right)$ and $\mathrm{S} / \mathrm{L}$ ratio $\left(X_{4}\right)$; (i) stirring speed $\left(X_{3}\right)$ and time $\left(X_{5}\right) ;(\mathrm{j}) \mathrm{S} / \mathrm{L}$ ratio $\left(X_{4}\right)$ and time $\left(X_{5}\right)$.

TABLE 7: Characteristics of maximum response $Y$.

\begin{tabular}{lccccccc}
\hline Response & Target value & Weight & $d_{i}(\%)$ & $d_{i_{\min }}(\%)$ & $d_{i_{\max }}(\%)$ & Cal. value & Exp. value \\
\hline$Y=$ REE $(\mathrm{ppm})$ & 8 & 1 & 100.00 & 93.17 & 100.00 & 7.99 & 7.12 \\
Desirability & - & - & 100.00 & 93.17 & 100.00 & - & - \\
\hline
\end{tabular}

$d_{i}$ : partial desirability of response $Y_{i} ; d_{i_{\min }}$ : minimal partial desirability of response $Y_{i} ; d_{i_{\max }}$ : maximal partial desirability of response $Y_{i}$; Cal. value: calculated value; and Exp. value: experimental value.

The optimal operating conditions allowing the maximum extraction were studied by the response surface methodology. The attained solubilization of $75 \%$ for REE was obtained by the following conditions: acidification of the ore by $\% \mathrm{HCL}=23$ for $45 \mathrm{~min}$ at a temperature of $44^{\circ} \mathrm{C}$, a solid/liquid ratio of $43 \%$, and a stirring speed of $233 \mathrm{rpm}$.

3.2. Optimization. To determine the optimal conditions acid concentration, solid/liquid ratio, reaction time, stirring speed, and temperature in order to define the optimal parameters allowing the maximum dissolution of the rare earths, the responses are optimized simultaneously using the desirability function included in the NEMROD software. It is based on the transformation of all responses obtained from different scales into an identical scale of desirability (individual desirability). The global desirability function $D$, which is taking into account both the requirements on all the responses $Y_{i}$, is the geometric mean of the individual desirability $d_{\mathrm{i}}$.

The desirability function varies in the interval $[0,1]$; the value 1 corresponds to the maximum satisfaction (desired value) and 0 corresponds to an unacceptable response $[19,21]$. The maximum of the function $D$ gives the best global compromise for all the responses in the studied domains and corresponds to optimal experimental conditions. All the information and results of the multicriteria optimization are given in Table 7. After calculation by the NEMROD software, the response surface corresponding to the maximum of the global desirability function $D$ is obtained. The optimal conditions allowing the maximum dissolution of the rare earths are temperature of $44^{\circ} \mathrm{C}$, time of $45 \mathrm{~min}$, S/L ratio of $43 \%$, stirring speed of $233 \mathrm{rpm}$, and acidification of the ore by $\% \mathrm{HCL}=23$. At these conditions, the predicted values of the responses calculated from the model were determined. In order to validate the model, three experiments were conducted under the same optimal conditions. The difference between the experimental and the predicted values was found to be minimal which indicates the good accuracy of the tested model.

\section{Conclusions}

In summary, the use of the surface response methodology in our study for the optimization of rare earth leaching from phosphate offers an opportunity to invent a recovery process of these strategic elements. Knowing that the response surface methodology has already proved its ability to improve various industrial processes of different industries, such as the food industry and the wastewater industry [22-25], this process could be integrated in the phosphate industry in order to valorize the phosphate as a secondary resource of rare earth element; however, in order to apply it in industry, an industrial prototype is essential to prove the technical and economic feasibility of the invented process. To reach leaching levels greater than or equal to $90 \%$, a second study must be conducted to increase acid concentration and temperature more than $23 \%$ and $44^{\circ} \mathrm{C}$, respectively, and decrease $\mathrm{S} / \mathrm{L}$ ratio less than $43 \%$. While the agitation and the duration of the reaction can be fixed on the values obtained in our study because they have less influence.

\section{Nomenclature}

RE: $\quad$ Rare earth

REE: Rare earth element 
BPL: $\quad$ Bone phosphate of lime

REMATOP: Laboratoire de Réactivité des Matériaux et Optimisation des Procédés

OCP: $\quad$ Office chérifien des phosphates

ICP-MS: Inductively coupled plasma mass spectrometry

ME: $\quad$ Minor element

RSM: $\quad$ Response surface methodology.

\section{Data Availability}

The authors confirm that the data supporting the findings of this study are available within the article.

\section{Conflicts of Interest}

The authors declare that they have no conflicts of interest.

\section{Acknowledgments}

The authors gratefully thank Reminex Managem laboratories in Marrakech, Morocco, for the chemical analyses and the help provided as well as the Center of Analysis and Characterization (CAC) at Cady Ayyad University, Marrakech, Morocco.

\section{References}

[1] M. K. Jha, A. Kumari, R. Panda, J. R. Kumar, K. Yoo, and J. Y. Lee, "Review on hydrometallurgical recovery of rare earth metals," Hydrometallurgy, vol. 165, pp. 2-26, 2016.

[2] X.-W. Huang, Z.-Q. Long, L.-S. Wang, and Z.-Y. Feng, "Technology development for rare earth cleaner hydrometallurgy in China," Rare Metals, vol. 34, no. 4, pp. 215-222, 2015.

[3] S. Wu, L. Zhao, L. Wang et al., "Simultaneous recovery of rare earth elements and phosphorus from phosphate rock by phosphoric acid leaching and selective precipitation: towards green process," Journal of Rare Earths, vol. 37, no. 6, pp. 652-658, 2019.

[4] L. Bilali, M. Benchanaa, A Outzourhit, and A Mokhlisse, "Application of microwave technology to the heat treatment of natural Youssoufia (Morocco) phosphates," Journal of Microwave Power and Electromagnetic Energy, vol. 43, no. 2, pp. 31-51, 2009.

[5] L. Bilali, "Application de la technologie microonde aux phenomenes de sechage et de pyrolyse des phosphates naturels de youssoufia," Thèse-Université Cadi Ayyad Faculté des Science Semlalia, Marrakech, Morocco, 2002.

[6] F. Pereira and E. Bilal, "Phosphoric acid extraction and rare earth recovery from apatites of the Brazilian phosphatic ores," Romanian Journal of Mineral Deposits, vol. 2, no. 85, pp. 49-52, 2012.

[7] S. Wu, L. Wang, L. Zhao et al., "Recovery of rare earth elements from phosphate rock by hydrometallurgical processes-a critical review," Chemical Engineering Journal, vol. 335, pp. 774-800, 2018.

[8] K. Ennaciri, A. Baçaoui, M. Sergent, and A. Yaacoubi, "Application of fractional factorial and Doehlert designs for optimizing the preparation of activated carbons from Argan shells," Chemometrics and Intelligent Laboratory Systems, vol. 139, pp. 48-57, 2014.
[9] R. Hakkou, M. Benzaazoua, and B. Bussière, "Valorization of phosphate waste rocks and sludge from the Moroccan phosphate mines: challenges and perspectives," Procedia Engineering, vol. 138, pp. 110-118, 2016.

[10] P. F. Bernath, “The spectroscopy of water vapour: experiment, theory and applications," Physical Chemistry Chemical Physics, vol. 4, no. 9, pp. 1501-1509, 2002.

[11] I. Bouatba, M. Benchanaa, M. E. Hammioui, and L. Bilali, "Physicochemical characterization of Moroccan phosphate and coke of a solid combustible," International Journal of Chemistry, vol. 8, no. 2, p. 72, 2016.

[12] R. Knubovets, Y. Nathan, S. Shoval, and J. Rabinowitz, "Thermal transformations in phosphorites," Journal of Thermal Analysis, vol. 50, no. 1-2, pp. 229-239, 1997.

[13] N. Pleshko, A. Boskey, and R. Mendelsohn, "Novel infrared spectroscopic method for the determination of crystallinity of hydroxyapatite minerals," Biophysical Journal, vol. 60, no. 4, pp. 786-793, 1991.

[14] I. Bouatba, L. Bilali, M. Benchanaa, and M. El-Hammioui, "Decadmiation of natural phosphates by heat treatment and hydrochloric acid," Asian Journal of Chemistry, vol. 28, no. 4, pp. 819-824, 2016.

[15] A. Baçaoui, A. Yaacoubi, A. Dahbi et al., "Optimization of conditions for the preparation of activated carbons from olive-waste cakes," Carbon, vol. 39, no. 3, pp. 425-432, 2001.

[16] K. Boujounoui, A. Abidi, A. Baçaoui, K. E. Amari, and A. Yaacoubi, "Flotation process water recycling investigation for the complex draa sfar sulphide ore, Morocco," Mine Water and the Environment, vol. 37, no. 1, pp. 75-87, 2018.

[17] G.-Q. Liu and X.-L. Wang, "Optimization of critical medium components using response surface methodology for biomass and extracellular polysaccharide production by Agaricus blazei," Applied Microbiology and Biotechnology, vol. 74, no. 1, pp. 78-83, 2007.

[18] R. Kim, H. Cho, K. Han, K. Kim, and M. Mun, "Optimization of acid leaching of rare-earth elements from Mongolian apatite-based ore," Minerals, vol. 6, no. 3, p. 63, 2016.

[19] I. Hammas-Nasri, K. Horchani-Naifer, M. Férid, and D. Barca, "Rare earths concentration from phosphogypsum waste by two-step leaching method," International Journal of Mineral Processing, vol. 149, pp. 78-83, 2016.

[20] M. Walawalkar, C. K. Nichol, and G. Azimi, "Process investigation of the acid leaching of rare earth elements from phosphogypsum using $\mathrm{HCl}, \mathrm{HNO}_{3}$, and $\mathrm{H}_{2} \mathrm{SO}_{4}$," Hydrometallurgy, vol. 166, pp. 195-204, 2016.

[21] Y. E. Maguana, N. Elhadiri, M. Bouchdoug, M. Benchanaa, and A. Boussetta, "Optimization of preparation conditions of novel adsorbent from sugar scum using response surface methodology for removal of methylene blue," Journal of Chemistry, vol. 2018, Article ID 2093654, 10 pages, 2018.

[22] S. Ahmad, V. V. Pathak, R. Kothari, A. Kumar, and S. B. N. Krishna, "Optimization of nutrient stress using C. pyrenoidosa for lipid and biodiesel production in integration with remediation in dairy industry wastewater using response surface methodology," 3 Biotech, vol. 8 , no. 8 , p. 326, 2018.

[23] S. Y. Guvenc, Y. Okut, M. Ozak, B. Haktanir, and M. S. Bilgili, "Process optimization via response surface methodology in the treatment of metal working industry wastewater with electrocoagulation," Water Science and Technology, vol. 75, no. 4, pp. 833-846, 2017.

[24] B. Kakoi, J. W. Kaluli, P. Ndiba, and G. Thiong'o, "Optimization of Maerua Decumbent bio-coagulant in paint industry 
wastewater treatment with response surface methodology," Journal of Cleaner Production, vol. 164, pp. 1124-1134, 2017.

[25] M. Yolmeh and S. M. Jafari, "Applications of response surface methodology in the food industry processes," Food and Bioprocess Technology, vol. 10, no. 3, pp. 413-433, 2017. 

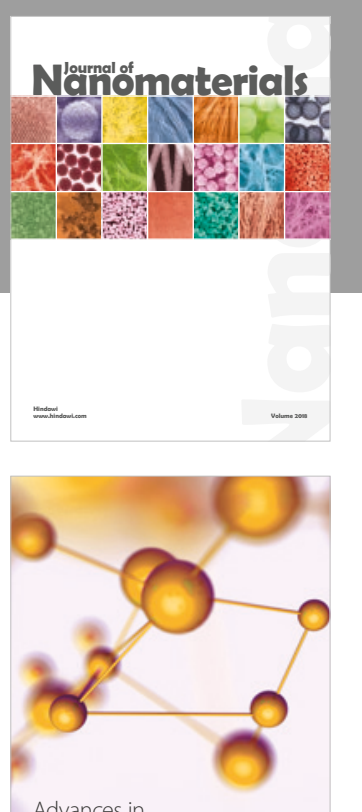

Physical Chemistry
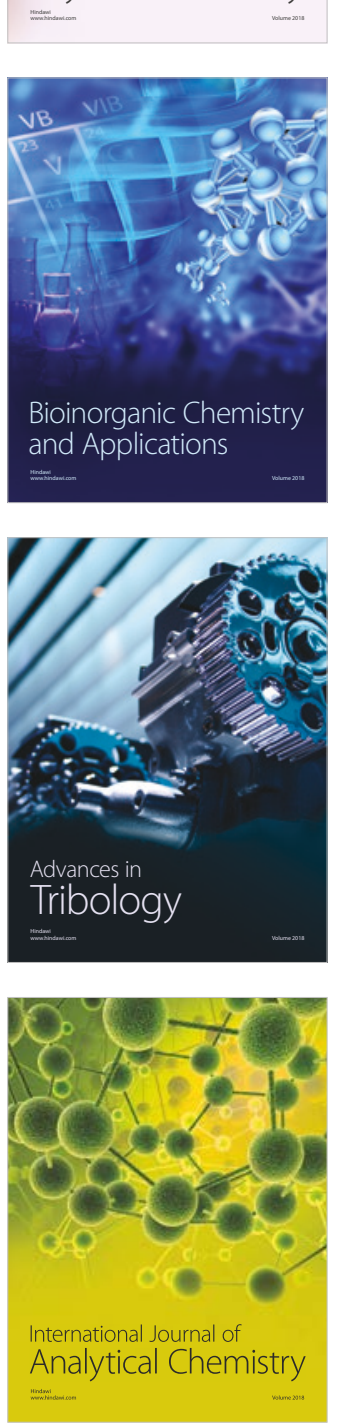

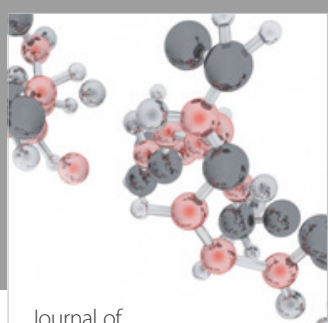

Analytical Methods

in Chemistry

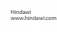

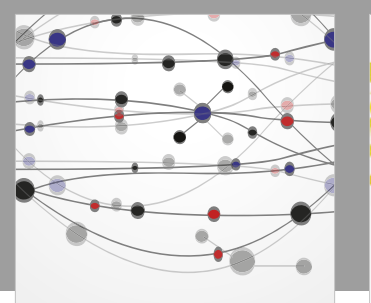

The Scientific World Journal

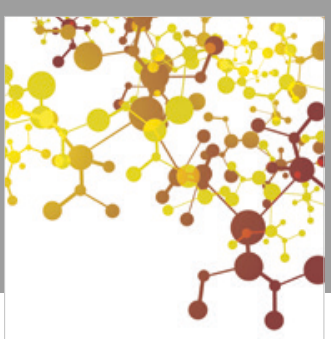

Journal of

Applied Chemistry
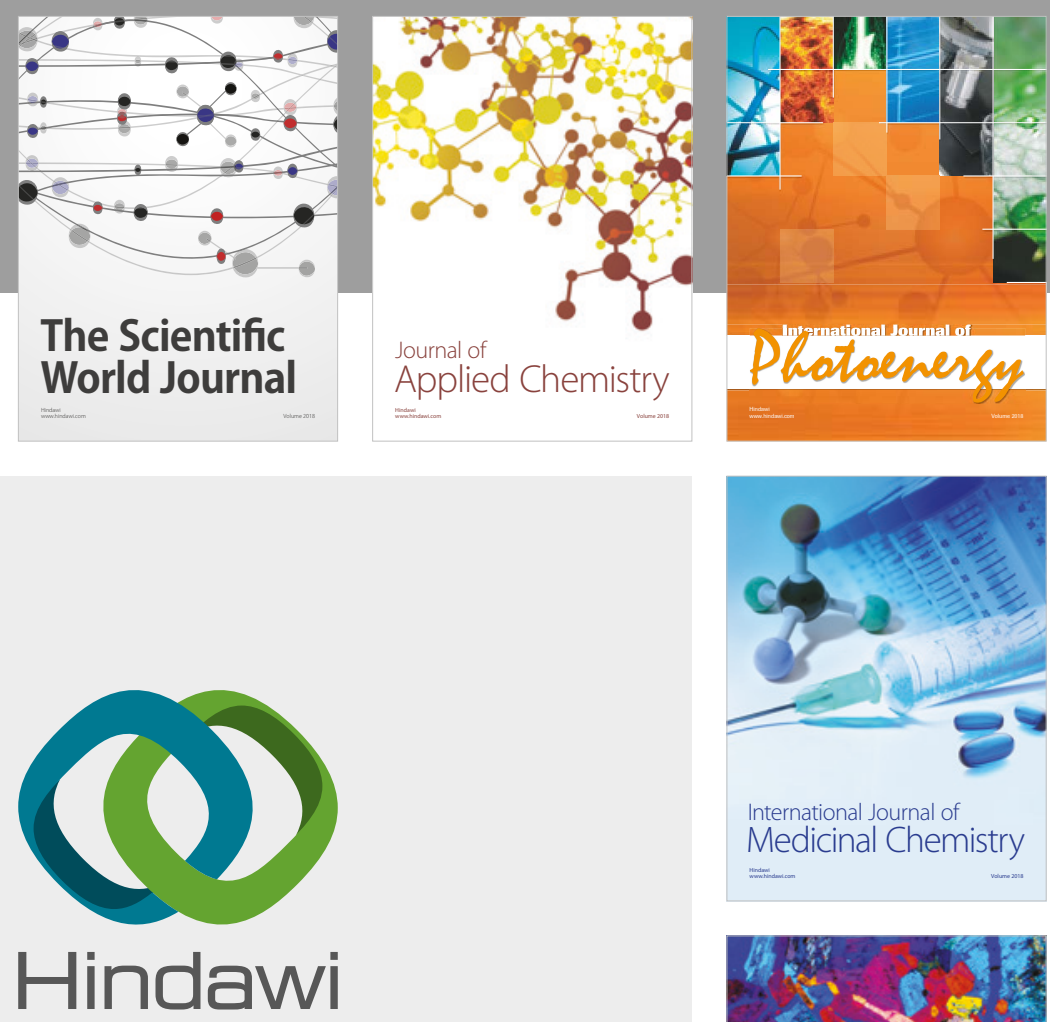

Submit your manuscripts at

www.hindawi.com
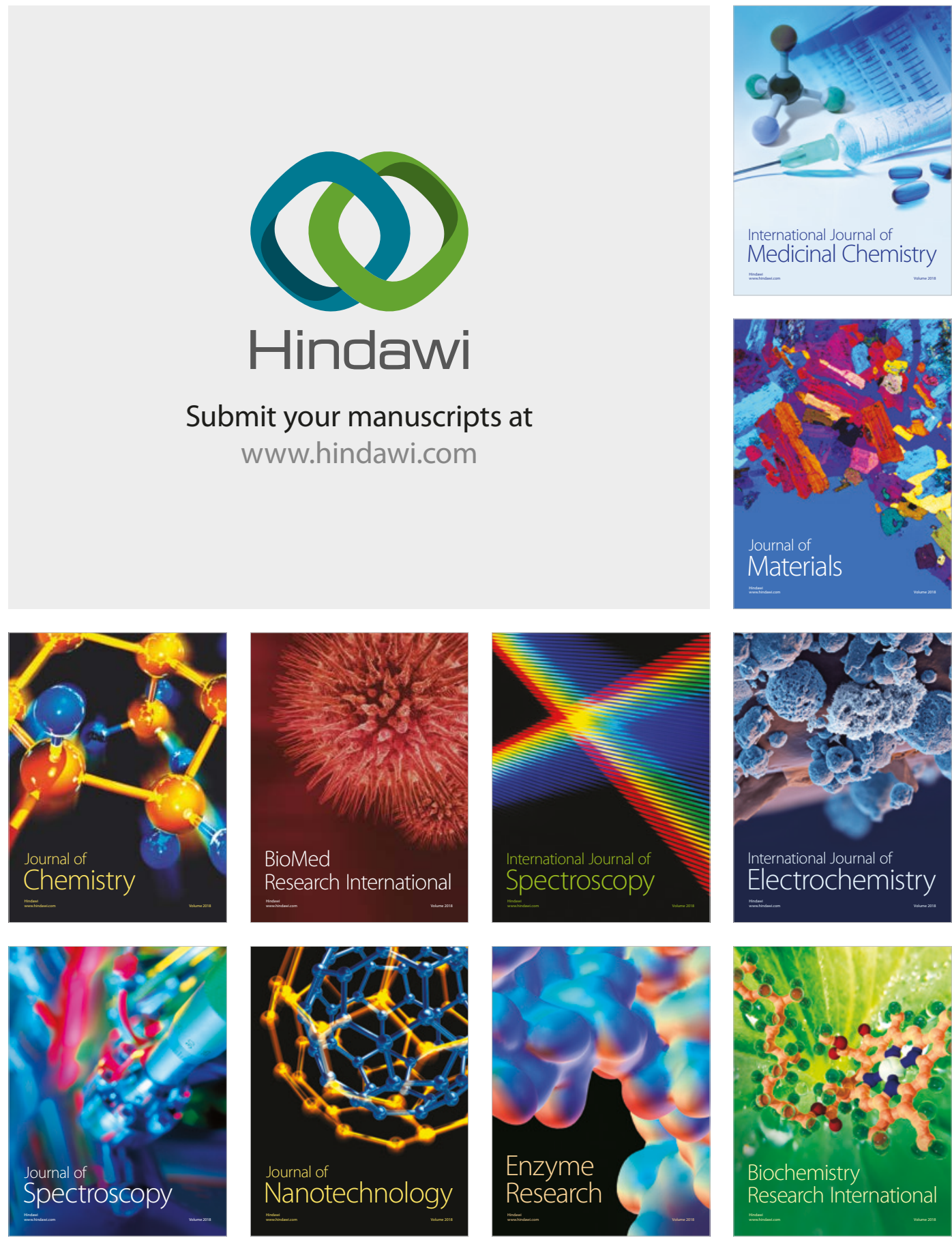
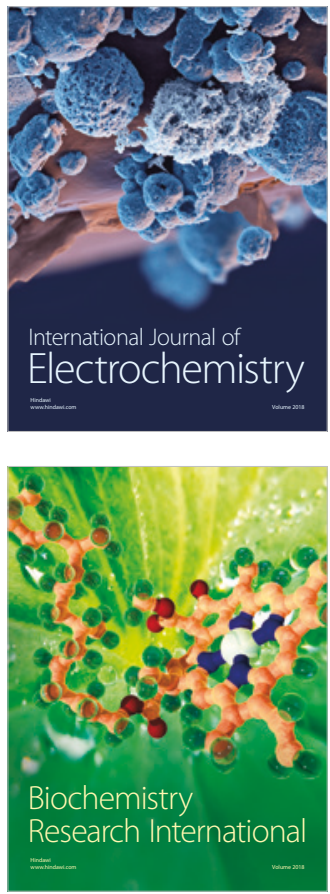